\title{
A CONSTITUIÇÃo HISTÓRICA DA SUBJETIVIDADE NAS REVISÕES DA TEORIA HEGELIANA *
}

The historical constitution of subjectivity in the revisions of the Hegelian theory

Humberto Schubert Coelho **

Die Ungleichheit, die im Bewußtsein zwischen dem Ich und der Substanz, die sein Gegenstand ist, stattfindet, ist ihr Unterschied, das Negative überhaupt. (...) Was ausser ihr vorzugehen, eine Tätigkeit gegen sie zu sein scheint, ist ihr eigenes Tun, und sie zeigt sich wesentlich Subjekt zu sein. (HEGEL, G. F. Phänomenologie des Geistes (Vorrede). Hamburg: Meiner, 1988, p. 28). ${ }^{* * *}$

Resumo: Não apenas pela natureza sistemática do projeto hegeliano como pela importância que a teoria da subjetividade inconfundivelmente assume para ele, a filosofia da história, como outros elementos, não pode ser satisfatoriamente compreendida sem uma análise conjunta do caráter histórico da subjetividade. Uma vez que subjetividade e intersubjetividade se sustentam e justificam mutuamente, toda teoria da história é sempre e necessariamente também uma teoria sobre as biografias, individuais, e as formas da cultura, das coletividades. Ao passo que estes finitos não produzem o todo, o todo tem de poder ser neles en-

* Os primeiros dois tópicos deste texto correspondem em parte à apresentação oral no VII Congresso Internacional da Sociedade Hegel Brasileira: A Filosofia da História de Hegel, 2013, com o título "Abordagens recentes do caráter histórico do homem".

** Doutorado em Ciência da Religião pela Universidade Federal de Juiz de Fora. Professor de filosofia na Universidade Federal de Juiz de Fora. Artigo recebido em 24/02/2014 e aprovado para publicação em 18/12/2014.

*** “A desigualdade que se estabelece na consciência entre o Eu e a substância - que é seu objeto - é a diferença entre eles, o negativo em geral. (...) O que parece ocorrer fora dela - ser uma atividade dirigida contra ela - é o seu próprio agir, e ela se mostra [assim] ser essencialmente sujeito." (HEGEL, G. F. Fenomenologia do Espírito (Prefácio). Trad. Paulo Meneses. Petrópolis: Vozes, 1988, p.40). 
contrado, de maneira que os princípios gerais, como o da história, estão sempre implícitos nos sujeitos e suas comunidades específicas. Somente assim entende-se que a filosofia da história é capaz de resistir às muitas críticas de anulação da individualidade e da incerteza quanto ao destino, oriunda do livre-arbítrio humano. Apresentaremos, portanto, alguns dos intérpretes contemporâneos do hegelianismo buscando enfatizar suas teorias da subjetividade como imprescindíveis para esboços de filosofia da história que preencham os critérios mais atuais.

Palavras-chave: História. Subjetividade. Autorrelação. Filosofia da história. Liberdade.

Abstract: Due to the systematic nature of the Hegelian Project and the unmistakably important role the theory of subjectivity plays in this project, the philosophy of history, as well as many other aspects of the system, cannot satisfactorily be understood without a joint analysis of the historical character of subjectivity. Since subjectivity and intersubjectivity are mutually supportive and justify each other, any theory of history is consequently and necessarily also a theory on biographies (individuality) and on the forms of culture (collectivity). Whereas these finites cannot produce the whole, totality has to be found in them so that the general principles, such as that of history, are always implicit in individuals and their specific communities. Only then can the philosophy of history resist against the numerous allegations of annihilation of individual freedom and the uncertainty of destiny, which derives from human free will. This article will therefore present some contemporary interpreters of Hegel whose theories of subjectivity are indispensable for the essays on the philosophy of history that comply with the most recent criteria.

Keywords: History. Subjectivity. Self-relation. Philosophy of History. Freedom.

\section{Introdução}

U ma filosofia da história pode começar comparando a invasão de Roma por Alarico à ocupação nazista de Paris. Pode interpretar estes eventos como empecilhos ou estímulos negativos ao progresso de alguma força que governa a história; e, contrariando as críticas de liberais como Popper e Mises ao historicismo, - tanto quanto a concepção do próprio Hegel - pode inclusive prever um "destino aberto", já que a fatalidade do progresso do espírito humano pode se caracterizar como aquele aspecto mais negativo da liberdade, sua abertura, ao invés de sua positivação nas instituições.

Hegel não é um individualista, mas um organicista. A liberdade do espírito é a instituição histórica, não o indivíduo.

Mas isso não significa absolutamente que todas as formas de hegelianismo, historicismo, ou todas as filosofias da história possíveis sejam organicistas, ou o sejam na mesma medida. 
Em certo sentido, toda teoria da história ou toda teoria social segue a inspiração historicista de dar sentido para o processo total das coletividades humanas, seja em Marx ou Simmel, em Rocholl, Zeller ou Deussen. E por que não ressaltar a "pequena" influência hegeliana sobre Ortega, Reale ou Weber como mais determinante do que aquelas mais explícitas ou mais recorrentes?

Se assumirmos que pensadores como Kierkegaard e Nietzsche desdobram sua obra a partir de um confronto com referências hegelianas, ${ }^{1}$ então é verdade que todo o pensar antropológico ou sobre a cultura se dispõe mais ou menos em função da revolução filosófica de Hegel.

Madame de Staël já atingira grande impacto com suas análises sobre a diferenciação latino-germânica, ${ }^{2}$ e Paul Hazard narrou a formação da Modernidade como crise de amadurecimento da consciência. ${ }^{3}$

E apesar de toda esta ampla influência sobre o pensamento posterior, a filosofia da história de Hegel converteu-se já no começo do século XX no "ponto fraco" de seu sistema. Como o sistema não pode sobreviver à retirada de suas partes, toda a estrutura metafísica jaz comprometida. Ao menos esta prerrogativa hegeliana parece ter garantido a sua respeitabilidade a ponto de evitar enxertos e reparos indiscriminados.

Uma vez que nosso objetivo é considerar alguns tratamentos mais recentes da filosofia da história e suas implicações, temos de nos haver com ao menos duas questões fundamentais: em que medida as intuições da filosofia da história, e consequentemente do modelo metafísico hegeliano, sobrevivem entre seus simpatizantes ou mesmo opositores contemporâneos; e de que maneira estes princípios desejáveis são purgados dos contornos mais problemáticos do hegelianismo.

Este trabalho pressupõe que estas questões mais práticas têm como raiz comum a conceituação da dimensão histórica da subjetividade.

\section{Prós e contras:}

Elementos menos originais como o tópico "Fundamentos geográficos da história mundial", na introdução da Filosofia da História, não deixam de carregar o traço marcante da largueza de visão hegeliana, ao passo que

\footnotetext{
${ }^{1}$ HOULGATE, Stephen. Hegel, Nietzsche and the Criticism of Metaphysics. Cambridge: Cambridge University Press, 1986.

2 STAËL, Madame de. De l'Allemagne. 2 Volumes. Paris: Garnier-Flammarion, 1968.

${ }^{3}$ HAZARD, Paul. La crise de la conscience européenne, 1680-1715. Paris: Fayard, 1961.
} 
transposições mais claras da nomenclatura hegeliana para o contexto histórico social, como sugerem os tópicos sobre "arte objetiva" e "arte subjetiva", nos fazem vacilar quando a capacidade de resistência da teoria sobre a história em sobreviver fora das condições específicas do ambiente hegeliano.

Aprofundando o bisturi sobre o corpus hegeliano deparamo-nos sem grandes sobressaltos com a sua veia empirista, no sentido de não basear sua análise na introspecção meditativa ${ }^{4}$ (como Descartes ou Fichte), e a necessidade de pautar toda a objetividade não apenas em sua condição de possibilidade transcendental, senão adicional e concomitantemente na publicidade possível desta objetividade na esfera da consciência intersubjetiva. ${ }^{5}$ Somente esta objetividade faz jus ao nome.

Houlgate foi quem mais profundamente analisou o aspecto crítico de Hegel diante da metafísica, comparando-o e aproximando-o de Nietzsche em questões significativas. Mas o mais importante, ele demonstrou o quão inverídica é a crítica de Nietzsche ao conceito hegeliano de subjetividade, já que este não guarda resquícios de transcendência (extramundana), sendo inteiramente radicada na realidade histórico-social, na vida vivida e compartilhada pela comunidade humana. ${ }^{6}$

As maiores dificuldades enfrentadas pelo hegelianismo se originam da índole muitas vezes dogmática de Hegel. É ela que motiva incontáveis pensadores a se afastarem das conclusões e premissas do organismo como um todo, inclusive comprometendo partes do sistema não tocadas por este espírito dogmático ou concepções obsoletas, como a visão de Hegel sobre a biologia. Por outro lado, sua assinatura psíquica é tão pervasiva que poucos dos projetos filosóficos posteriores conseguiram dele se afastar, ou não se afastaram tanto quanto supunham.

O que vale para Hegel vale para o historicismo. Ao passo que os contornos dogmáticos deste último assustam, sua presença se faz sentir quase invariavelmente. É megalomaníaco ao tentar apreender o destino, prever

\footnotetext{
${ }^{4}$ HOULGATE, Stephen. Hegel, Nietzsche and the Criticism of Metaphysics, p. 145.

${ }^{5}$ Problema a que me dediquei com mais afinco em COELHO, Humberto Schubert. A insuficiência do sujeito na metafísica da subjetividade. Theologica 48, 1.

${ }^{6}$ HOULGATE, Stephen. Hegel, Nietzsche and the Criticism of Metaphysic, p. 151:The subjectivity which metaphysics previously conceived as distinct from human language, as 'transcendent', is now conceived by Hegel as constituted in human thought and language. The subject for Hegel thus has no other-worldly connotations; it does not reside beyond the activity of man in history, but is immanent in that history. Like Nietzsche, Hegel is critical of the view that there is any subjectivity which transcends the historical specifity of human existence. He is critical of the view that presents the human subject as a soul independent of social and historical conditions, and he is critical of the view that makes human existence depend on an all-powerful cosmic subjectivity. However, unlike Nietzsche, Hegel does not simply invert the hierarchy and construe the notion of man's unified subjectivity as a fiction produced by human existence.
} 
o futuro, mas é modesto e extremamente realista ao colocar o homem de algum modo sob a contenção do processo maior da sociedade, fazendo com que o gênio seja o porta-voz do seu século, a súmula de todas as experiências absorvidas e encetadas pela sua cultura.

Mas é claro, o gênio não é "resultado" passivo de seu meio, senão a sua expressão máxima, ${ }^{7}$ atestado da subjetividade que caracteriza a vida do Espírito. Ao resumir seu tempo e comunidade, ele confirma e eleva sempre a capacidade humana de se apreender e se construir. Uma forma de autoconsciência do sujeito enquanto liberdade, pertencente a um mundo social originado e destinado à liberdade.

Ao menos neste sentido é radicalmente falsa a acusação de Marx de que o ponto de vista hegeliano faria da história uma subordinada da metafísica, da realização humana uma subsidiária da ideia absoluta. A concepção hegeliana de história é bem mais concreta e próxima da de Marx do que este estava pronto a reconhecer; é ao mesmo tempo pragmática e teleológica, guarda em si o dever-ser da humanidade, mas este "destino" precisa ser atualizado pela livre ação dos indivíduos, pelo seu trabalho (o tema da dialética do senhor e do servo).

Por outro lado, críticas relativistas e libertárias se dirigem fundamentalmente contra o preconceito igualmente falso de que a filosofia da história de Hegel seria uma imposição dogmática e fechada de um tipo cultural específico. Como se reconhece hoje, mesmo as supostas versões libertárias da teoria social e comunicativa são de algum modo enviesadas pela crença tipicamente ocidental (greco-cristã) de que as idiossincrasias podem ser acomodadas pelo diálogo com vistas à colaboração em prol do interesse comum ou respeito para com os interesses individuais.

Não estando, portanto, mais culturalmente condicionado do que as propostas pós-modernizantes do século XX, o hegelianismo, como qualquer outro modelo de pensamento, prescinde de esforço para escapar a esta acusação.

Libertários, por sua vez, descobrem aos poucos que sua própria utopia de uma sociedade sem fins últimos não difere tanto de uma cujo fim último é a liberdade. ${ }^{8}$

\footnotetext{
${ }^{7}$ BEISER, Frederic. Hegel's Historicism. In: BEISER, Frederic (Ed.). Cambridge Companion to Hegel.Cambridge: Cambridge University Press, 1993.

${ }^{8}$ BEISER, Frederic. Hegel's Historicism. In: BEISER, Frederic (Ed.). Cambridge Companion to Hegel, 1993, p. 279: the end of history is the selfawareness of freedom. This goal is not purely formal and abstract, as if Hegel thinks that each culture achieves it in its own unique and incommensurable manner. For in his Philosophy of Right he outlines in very specific terms the necessary conditions for the realization of freedom. A state that is to achieve this end must fulfill very definite conditions, viz., it should provide for popular representation, it should have a written constitution limiting the powers of the central authority, it should permit liberty of press and freedom of conscience, and so on. Clearly, not any constitution or culture fulfills these conditions. In general, it is important to see
} 
A metafísica de Hegel não apenas fundamenta, como é indissociável da filosofia da história. Esta última é um dos modos de explicitação da metafísica, tal qual o é a filosofia do direito. É especialmente em Filosofia da História que se aclara o papel não subjetivo e não pessoal do Espírito. Mais do que isso, enfatiza-se o fato de ele surgir como abstração intermediada pela cultura; não tem existência prévia como um Deus completo anterior à criação e ao processo histórico. ${ }^{9}$

Quanto à estrutura, pode-se dizer que a filosofia da história alia o processo metafísico da fenomenologia da consciência e do Espírito à análise empírica minuciosa da história da cultura, tendo como resultado um organismo que foi qualitativa e quantitativamente impactante, capaz de se impor por décadas. E as implicações desta consistência multidimensional se fazem sentir nos debates mais atuais. ${ }^{10}$

that Hegel did not reject the tradition of natural law, which posited certain universal and necessary standards of right and wrong. Rather, he simply transformed and reinterpreted this tradition. Instead of seeing natural law as an eternal law above the process of history, Hegel historicizes it, so that it becomes the purpose of history itself. This then gives him an absolute standard by which he can appraise all the different cultures and constitutions of world history. They are good or bad according to whether they contribute toward the self-consciousness of freedom.

${ }^{9}$ BEISER, Frederic. Hegel's Historicism. In: BEISER, Frederic (Ed.). Cambridge Companion to Hegel, 1993, p. 291.

${ }^{10}$ Convém citar ao menos um exemplo em que a discussão sobre a filosofia da história é imprescindível para a correta diagnose de problemas contemporâneos, ainda que estas discussões não deixem de ser elas mesmas críticas atualizadas do hegelianismo. Veja-se METTENHEIM, Kurt von. Conjunções Críticas da Democratização: as Implicações da Filosofia na História de Hegel para uma Análise Histórica. Instituto de Estudos Avançados da Universidade de São Paulo, USP.p. 24.: Este artigo procurou utilizar hipóteses causais e perspectivas comparativas da Filosofia da História, de Hegel para compreender o caráter político e o conteúdo substantivo das conjunções críticas da democratização na história da Europa Ocidental. Ao tentar esclarecer as hipóteses de Hegel e ao rever a evidência empírica acumulada desde suas análises, este breve exercício sugere que os conceitos de conjunções críticas e path dependence possam ajudar a descrever as mudanças periódicas e súbitas que reorganizam as relações entre Estado e sociedade. Nestas relações, as conjunções críticas são raras; aglutinam, entretanto, fenômenos políticos comparáveis que 1) são causa e consequência de mudanças na consciência popular de justiça; 2) redefinem a democracia remetendo-a a princípios básicos; 3) são determinadas por fatores tipicamente políticos, tais como negociações, pactos e acordos; 4) compartilham de uma imediação e de uma transparência singulares nas relações entre Estado e sociedade. Esta conclusão revê as hipóteses causais, as perspectivas comparativas e a evidência histórica apresentadas neste artigo.

Talvez a conclusão mais importante deste exercício seja que a democracia é um princípio não restrito apenas a determinado regime formal ou a um período histórico particular. Ao contrário, as conjunções críticas têm redefinido as relações entre Estado e sociedade na medida em que a transparência, a imediação e o conteúdo substantivo das reivindicações populares diretas reformularam princípios democráticos. Os gregos antigos criaram princípios democráticos através de simples regras randômicas de representação, que se entrelaçaram com os vínculos tribais. Em Roma, os cristãos formaram uma comunidade baseada na aceitação universal da "regra de ouro". Na Europa Medieval, os reinados itinerantes colocavam os agentes reais in situ e não atrás das muralhas dos castelos e das barreiras burocráticas, enquanto que hereges, reformadores urbanos, elites da igreja e realeza atendiam às novas demandas populares de mudança do status quo. A Reforma Protestante tentou inicialmente eliminar toda intermediação entre as comunidades e Deus, criando-se então as grandes 
É correto dizer que:

Em sua proposta historiográfica, Hegel indica, como que a partir de um material primário, a história original - os relatos elaborados por aqueles que vivenciaram os fatos - desenvolve-se uma espiral que vai se sofisticando, passando-se, em seguida, para uma história refletida, que já sabe de si e se reelabora a partir de conceitos, e, posteriormente, alcança, em seu cume, a história propriamente filosófica. ${ }^{11}$

Este movimento é e tem de ser possibilitado pela estrutura da subjetividade, que é desde sempre tanto histórica quanto intersubjetiva. Podemos ver na história humana as camadas identificadas por Hegel (o dado bruto, a pragmaticidade, a reflexão crítica sobre os fatos e a conceituação final em uma teoria da história) porque somos igualmente capazes de interpretar a historicidade individual segundo estas mesmas etapas. Isto é 1- vivenciamos os fatos de maneira mais ou menos inconsciente ou passional, 2- intelectualizamo-los para extrair aprendizado prático sobre o eficaz e o ineficaz, o "bom" e o "mau", 3- refletimos criticamente sobre nossas narrativas históricas, elaborando questionamentos sobre nossa própria memória em sentido histórico, e finalmente 4- traçamos o perfil de funcionamento de nossa história em geral, o sentido de nossas vidas.

Também digna de atenção é a recepção e reinterpretação mais recente da astúcia da razão, um dos conceitos mais duramente criticados e usualmente relacionado ao "dogmatismo anti-individualista" de Hegel.

Em minha tese de doutorado ${ }^{12}$ discuti longamente a raiz protestante da positividade do mal na figura do diabo em Jakob Böhme e J. W. Goethe. Esta pesquisa deixou clara a perspectiva neoplatônica que se infiltrou no protestantismo a partir de Böhme, Goethe e outros, contrapondo-se (em variados graus de intensidade) ao relativo pessimismo de Lutero. E como Schelling foi o responsável por transcrever esta intuição neoplatônica da mística luterana para o vocabulário filosófico altamente técnico do Idealismo nascente.

Olhando para o futuro observamos que teóricos políticos e do direito também reservam um lugar para a positividade das experiências mal sucedidas da história.

religiões nacionais, que definiram o primeiro sistema de Estado Moderno na Europa. Finalmente, a Revolução Francesa deu por obsoletas antigas reivindicações de legitimidade, lei e tradição, ao eliminar todas as ideias e instituições do passado que pudessem interferir com a relação direta entre cidadão e governo.

${ }^{11}$ BAMBIRRA, Felipe M. A metodologia hegeliana do estudo da história e do estado: a ascensão dialética no embate entre a razão e a paixão. Anais do XIX Encontro Nacional do CONPEDI. Fortaleza, 2010, p. 2.

${ }^{12}$ COELHO, Humberto Schubert. Livre-arbitrio e sistema; Conflitos e conciliações em Böhme e Goethe. Juiz de Fora: UFJF, 2012. 
Um exemplo instrutivo é o de nosso magistral Miguel Reale, que defende claramente uma espécie de "astúcia da razão" na formação do direito, bem mais por questões de princípios e realismo do que por uma fé na razão. Segundo ele, devemos confiar nas leis e na ordem ainda quando elas falham, pois assim exemplificamos valores ainda maiores do que os representados por leis justas. De outro modo, no entanto, nossa ideia de justiça nos força a operar contra a civilização. ${ }^{13}$

\section{O sujeito na história e a história do sujeito:}

Em "A história da juventude de Hegel" Dilthey profere uma de suas inspiradas sentenças acerca da atitude filosófica de Hegel e seu amigo Schelling.

Ambos vêm de lados distintos, Schelling da natureza e Hegel da história, e se encontram no mesmo ponto. O objeto da filosofia é a totalidade universal. Nesta as oposições da generalidade e da particularidade, do infinito e do finito são canceladas. […] Nesta fórmula o panteísmo de Espinosa progride: o conceito morto da substância se define com razão, pois a totalidade universal só se apresenta nas categorias do pensamento, as quais determinam a percepção. ${ }^{14}$

Em tempos recentes a hermenêutica filosófica superou os aspectos mais didáticos ou mesmo simplórios do historicismo, entendendo as correntes filosóficas como constelações onde a ausência de estrelas relativamente pequenas compromete a figura. Ao invés de uma escada contínua de Kant a Hegel, sabemos que o Idealismo é um organismo no qual as figuras de Fichte, Jacobi, Schiller, Goethe, Schelling, Hölderlin ou Reinhold não podem ser subsumidas como etapas prévias do sistema hegeliano.

Afinal, o Idealismo em geral nem era tão acrítico quanto o fizeram parecer o neokantismo, nem está tão apartado de Kant que também não possa receber incólume e com proveito os ataques neokantianos na forma de revisão, ao invés de demolição. (Henrich, Houlgate)

A ideia de Henrich de revisar e complementar as filosofias destes autores através da perspectiva dos demais expressa, portanto, uma transformação altamente desejável para a aplicação das questões levantadas pela filosofia clássica alemã. Questões que sabidamente são perpassadas e estão em função da subjetividade, já que seu objetivo fundacionista assume-se como necessariamente sistemático e totalizante, radicado na apresentação da condição de possibilidade do saber e da ação humana.

\footnotetext{
${ }^{13}$ REALE, Miguel. Lições preliminares de Direito. São Paulo: Saraiva, 2010, p. 298-299.

${ }^{14}$ DILTHEY, Wilhelm. Gesammelte Schriften. Göttingen: Vandenhoeck \& Ruprecht, 1968. Bd. IV, p. 205.
} 
Subjetividade é a capacidade de ressoar a história da sociedade vivida, de modo que esta produz o indivíduo, mas não de forma mecânica, senão em relação com a disposição prévia da subjetividade.

Heidegger, na medida em que é ainda um discípulo de Hegel, caracterizou bem esta situação na forma de sua análise das disposições ontológicas. Podemos dizer sem reparos que, para Hegel, o homem é um ser para a sociedade, um ser para a cultura ou um ser para a história. ${ }^{15}$

Adicionalmente e por outro lado, o indivíduo não reflete a história passivamente. Ela é o médium no qual ele vive, mas suas características particulares e a perspectiva irredutível de primeira pessoa que o diferencia de todo outro sujeito faz com que este seu ressoar da história e da sociedade seja próprio, único e original. A subjetividade não prescinde da cultura para formar o indivíduo, mas a cultura tampouco forma o indivíduo. É antes ele que se forma na cultura.

O motivo desta simbiose não é difícil de apreender. Conforme Ricoeur, "preciso da história para sair de minha subjetividade privada e experimentar em mim mesmo e para além de mim mesmo o ser-homem, o Menschsein. [...] Eis a palavra suprema: o sentido. Pela história procuro justificar o sentido da história "da" consciência."16

Henrich está de acordo com as críticas do último século ao excesso de pretensões da metodologia filosófica, e, precisamente por esta razão, reafirma a vocação da filosofia como formadora ou cooperadora da sabedoria em suas várias dimensões: na forma de modéstia epistemológica, ou das meditações sobre a liberdade e o sentido da vida. ${ }^{17}$

Em face de uma filosofia mais atida ao sentido da vida, a história geral é também a orquestração dos incontáveis sentidos particulares das biografias. A diferença entre se exigir ou prescindir de uma filosofia da história está, então, não apenas na aceitação de uma tendência providencial do logos, como de um desdobramento da necessidade tipicamente humana

\footnotetext{
${ }^{15}$ GOODIN, R.; PETTIT, P.; POGGE, T. (Ed.) A Companion to Contemporary Political Philosophy. Malden: Blackwell, 2007. Vol. II, p. 41: "For Hegel, as for Rousseau, ethical life can only be sustained through involvement in a concrete community with its culture, values and forms of life. By the same token, the moral or rational will should not be seen as something absolutely opposed to the natural inclinations of the biological individual, as it is for Kant, but rather as the result of a rationalizing of these inclinations. Whereas the particular impulses of the human organism inevitably ignore the ethical demands of society, the socially constituted interests of mature individuals already reflect the requirements of the community, even when they are not necessarily in harmony with one another. The will, as opposed to mere impulse, is 'particularity reflected into itself and so brought back to universality, i.e. it is individuality' (Hegel, [1821] 1952, p. 23). The individual is a product rather than a premiss of the social order."

${ }^{16}$ RICOEUR, Paul. História e Verdade. Rio de Janeiro: Forense, 1968, p. 37.

${ }^{17}$ HENRICH, Dieter. Denken und Selbstsein: Vorlesungen über Subjektivität. Frankfurt am Main: Suhrkamp, 2007.
} 
de significar a vida, o que acaba produzindo diversas possibilidades interpretativas para o conjunto ou somatório dos sentidos atribuídos à vida. Dito de forma mais direta, é talvez possível diagnosticar as disposições ontológicas básicas que se relacionam ao sentido vital, deduzindo-se daí uma ou várias forças contribuintes com o sentido da história. ${ }^{18}$

Em Hegel, como em Schelling e até certo ponto em Fichte, o Eu não pode fundamentar a si mesmo ex nihilo. ${ }^{19}$ A dimensão do mundo e dos outros sujeitos é o que lastreia a própria subjetividade por oposição. A liberdade se dá por conflito e negociação com algum outro, de modo que a história individual é sempre uma revelação da natureza do sujeito particular e da natureza geral.

Ora, como o sistema hegeliano pressupõe e demonstra a possibilidade de uma síntese final entre o finito e o infinito, surge quase como corolário a possibilidade de se traçar uma filosofia da história com pretensões de objetividade. Mas como as já anunciadas correções críticas de Hegel propõem, este e outros aspectos do sistema podem ser revisados sob diversos crivos, sendo o kantiano o preferencial entre os investigadores da subjetividade. Desta forma, a filosofia da história pode subsistir ainda como o espaço das interpretações (em caráter assumidamente hipotético) dos fins absolutos, isto é, compartilhados pela humanidade e pela natureza ou mutuamente implicados por elas.

Para investigar a filosofia da história hodiernamente possível precisamos, portanto, mergulhar no estudo das autorrelações subjetivas, e tentar transpor estas autorrelações ao plano social. Mas isto é algo que só deve ser intentado enquanto abstração.

Não há, contudo, qualquer dificuldade em extrair este ponto de vista não dogmático e crítico do hegelianismo, já que não apenas ele se permite tal viés como igualmente o trabalho de inúmeros pensadores posteriores o viabilizou.

Em mais uma sentença feliz de Ricoeur:

Constitui sem dúvida o mérito das filosofias da negatividade, a partir de Hegel, o haver-nos reposto na senda de uma filosofia do ser capaz de libertar-se da coisa e da essência. Todas as filosofias clássicas são, em grau maior ou menor, filosofias da forma, seja a forma como ideia, seja como substância e quididade. A função da negação é tornar difícil a filosofia do ser, como Platão, em primeiro lugar, o reconheceu no Sofista: "o ser e o não-ser igualmente nos embaraçam". Sob a pressão do negativo, das ex-

\footnotetext{
${ }^{18}$ Com poucos reparos podemos aplicar esta definição a autores como Roque Spencer Maciel de Barros, que identifica duas forças primordiais na vida ético-política: individualismo e coletivismo. Acerca disso elaborei um artigo para o primeiro congresso Luso-galaico-brasileiro. COELHO, H. S. A ideia de homem como totalidade em Roque Spencer Maciel de Barros. In: Actas do I Congresso do pensamento Luso-galaico-brasileiro (1850-2000). Vol. II, p. 335.

${ }^{19}$ HENRICH, Dieter. Bewusstes Leben.Stuttgart: Reclam, 1999, p. 126.
} 
periências do negativo, temos de reconquistar uma noção de ser que seja antes ato que forma, afirmação viva, poder de existir e de fazer existir. ${ }^{20}$

Sem abandonar ou limitar a possibilidade de se constituir uma história que subsume o sujeito, a moderna teoria da subjetividade lembra que esta esfera precisa ser fundamentada na forma como a subjetividade se constitui historicamente, em biografia.

\section{Biografia como autorrelação:}

No entender de Düsing, "a evolução dos modelos de autoconsciência apresenta ao final como no começo da história idealista da autoconsciência uma gênese gradativa de modos cada vez mais complexos de autorrelação."21

A grande contribuição de Hegel foi demonstrar que o Eu não poderia ser dado como evidência imediata. Até porque, esvaziou-se a possibilidade de constituir o sujeito (ou qualquer outro conceito) a partir de categorias fixas ou processos cujo ponto de partida possa ser definido. $\mathrm{O}$ sujeito passa a ser o processo dialético por excelência, o qual só se permite investigar a partir de "conceitos de modalidade", "formas particulares de uma relação de circunstancialidade interior e exterior", de modo que "cada necessidade é também sempre relativa". ${ }^{22}$

Todos os processos agrupados sob a autoconsciência se manifestam como autorrelações, diferenciando-se tão somente pela sua funcionalidade Nas palavras de Düsing os modelos de autoconsciência são as inúmeras formas e modos de autorrelação.

A biografia é, assim, o modo de autoconsciência estabelecido em função do tempo, assim como o caráter é um modo de autoconsciência estabelecido em função da eticidade. Tais modelos não esgotam de modo algum os aspectos que pretendem isolar, de modo que se estabelecem em grande parte por necessidades didáticas, para termos de análise.

Para entendermos corretamente o que é uma autorrelação devemos estudar a moralidade com zelo especial, pois é aí que o drama intrincado das autorrelações atinge o ápice da transparência.

No conflito entre vontade, instinto, razão e elementos subsidiários, como os costumes, o sujeito tem exposto diante de si um conjunto vivo e claro das relações entre diversas dimensões de si. Sua consciência apetitiva entra, não raro, em conflito com a consciência racional; é comum que a consciên-

${ }^{20}$ RICOEUR, Paul. História e Verdade, p. 337.

${ }^{21}$ DÜSING, Klaus. Subjektivität und Freiheit: Untersuchungen zum Idealismus von Kant bis Hegel. Stuttgart: Frommann \& Holzboog, 2002, p. 28-29.

${ }^{22}$ HENRICH, Dieter. Hegel im Kontext. Frankfurt am Main: Suhrkamp, 1967, p. 162. 
cia social se contraponha à consciência volitiva individual, produzindo-se rusgas psicológicas já bem identificadas ao longo da história das pesquisas psicológica e moral.

Se há no homem eticidade suficiente para afirmar a sua responsabilidade, então a razão tem de ter autonomia sobre a vontade. O que é julgado correto precisa poder suplantar o que é desejado. ${ }^{23}$

Mas a autonomia da racionalidade prática não esgota, como propôs Kant, o princípio causal da moralidade. Schiller acrescentou a ela a importante noção de que, conforme a tradição ocidental desde Agostinho, a boa vontade é que fundamenta a ação como boa. A vontade pode ser patrocinada por uma inclinação ou pela razão, ou por ambas, mas o que importa na definição de uma ação como ética ou não permanece sendo a vontade. ${ }^{24}$

Esta percepção de Schiller é crucial para a compreensão da autoconsciência como autorrelação, que pode dispor para si modos racionais, modos apetitivos ou modos sociais de autorrepresentação, mas que se preserva sempre como subjetividade capaz de eleger para si o modo circunstancialmente apropriado. E tal eleição é constitutiva do que chamamos ora de história individual, ora de sentido da vida.

A liberdade não é a capacidade de optar por um entre dois caminhos de uma encruzilhada. Nem sequer começa a ser descrita pela opção por fruta ou ovos no café da manhã. Ainda que tais eventos incluam uma deliberação, ela é patentemente desimportante, relegada ao automatismo, à conveniência ou necessidade mais premente.

O que de fato caracteriza a liberdade é o seu uso próprio e puro, alheio às contingências cotidianas que dela exigem apenas uma rápida e desinteressada anuência ou reprovação. De outro modo estamos efetivamente fadados a subjugá-la às inclinações psicológicas, biológicas ou aos preconceitos adquiridos culturalmente.

Em outras palavras, se a liberdade não é a faculdade de autoconstrução da subjetividade em jogo com a sociedade e a história, então se limita a decisões binárias que dão razão aos estudos das neurociências que a pretendem dissecar em um tipo de consciência de opções, matando-a e "explicando-a" cientificamente como impressão psicológica.

Ela se revela em toda a sua extensão nos momentos de crise, nas decisões graves em que o destino, a história individual ou coletiva está em jogo, ou naquelas questões aparentemente pequenas em que o estilo de vida pode ser definido, como a opção por uma conduta ética, pelo bom humor ou

\footnotetext{
${ }^{23}$ De nada serve que a razão deduza corretamente o bom (principium diiudicationis bonitatis), se não tem o poder de executá-lo. Daí que a autonomia da razão está em que o homem não haja conforme interesse, mas possa agir conforme a retidão (principium executionis bonitatis). HENRICH, Dieter. Selbstverhältnisse. Stuttgart: Reclam, 1982, p. 14.

${ }^{24}$ Ibid. p. $45-46$.
} 
pela fé. Em ambos os casos, a liberdade é a capacidade humana de criar e fundar o projeto que o sujeito tem para a sua própria história. ${ }^{25}$

A liberdade, e somente ela, é a faculdade pela qual o homem pode dar sentido para sua vida; prescrever para si um futuro e reconstruir subjetivamente os fatos do passado a fim de lhes emprestar significação vital e referências para o amadurecimento. A história é o conjunto dos eventos físicos, psicológicos ou sociais sob o ponto de vista da liberdade.

\section{Conclusão:}

Como a subjetividade é a condição humana de interpretação da vida a partir de uma perspectiva de primeira pessoa, incluindo aí a capacidade de execução das deliberações sobre esta vida tomada como subjetiva, toda a história individual é a história de um sujeito. Uma biografia só está pronta quando acaba, mas é desde o princípio diagnosticável como trajetória de um sujeito livre.

A história geral é consequentemente tão mais indefinível e imprevisível quanto maior é o grau de complexidade de um quadro composto pela relação orgânica de uma multidão dessas construções biográficas. Mas não pode ser puramente imprevisível, já que é também o estado macroscópico do espírito humano, cuja trajetória é pautada pelo livre desenvolvimento de si. É, então, também e a par de todas as ressalvas da pós-modernidade, identificável como o quadro geral do desdobramento e desenvolvimento da humanidade.

\section{Bibliografia:}

BAMBIRRA, Felipe M. A metodologia hegeliana do estudo da história e do estado: a ascensão dialética no embate entre a razão e a paixão. Anais do XIX Encontro Nacional do CONPEDI. Fortaleza, 2010.

BEISER, Frederic (Ed.). Cambridge Companion to Hegel. Cambridge: Cambridge University Press, 1993.

COELHO, Humberto Schubert. A ideia de homem como totalidade em Roque Spencer Maciel de Barros. Actas do I Congresso do pensamento Luso-galaico-brasileiro (1850-2000)), Actas do I Congresso Internacional. Lisboa: Casa da Moeda, 2009.

${ }^{25}$ HENRICH, Dieter. Denken und Selbstsein. p. 352: “Liberdade, portanto, não é a decisão de fazer ou negligenciar isto ou aquilo que estiver em jogo, mas sim assumir nessa decisão uma determinada maneira de agir e nela viver, de modo a ser em relação a ela a mesma ou outra pessoa. Uma decisão tomada livremente implica em uma perspectiva de vida. Caso não suceda apenas provisoriamente, de modo a ser abandonada na próxima ocasião, esta decisão afeta também profundamente todo o comportamento de uma pessoa." 
. A insuficiência do sujeito na metafísica da subjetividade. Theologica 48, 1 (2013) p. 157-169.

. Livre-arbítrio e sistema; Conflitos e conciliações em Böhme e Goethe. Juiz de Fora: UFJF, 2012. Tese de doutorado defendida na Universidade Federal de Juiz de Fora. Programa de Pós-graduação em Ciência da Religião, 2012.

DILTHEY, Wilhelm. Gesammelte Schriften. Göttingen: Vandenhoeck \& Ruprecht, 1968.

DÜSING, Klaus. Subjektivität und Freiheit: Untersuchungen zum Idealismus von Kant bis Hegel. Stuttgart: Frommann\&Holzboog, 2002.

GOODIN, R.; PETTIT, P.; POGGE, T. (Ed.) A Companion to Contemporary Political Philosophy. Malden: Blackwell, 2007.

HAZARD, Paul. La crise de la conscience européene, 1680-1715. Paris: Fayard, 1961.

HEGEL, G.W.F.Phänomenologie des Geistes. Stuttgart: Reclam, 1999.

. Werkein 20 Bänden. Ed. MOLDENHAUER, Eva; MICHEL, Karl M. Frankfurt am Main: Suhrkamp, 1970.

HENRICH, Dieter. Bewusstes Leben. Stuttgart: Reclam, 1999.

. Denken und Selbstsein: Vorlesungen über Subjektivität. Frankfurt am Main:

Suhrkamp, 2007.

. Hegel im Kontext. Frankfurt amMain: Suhrkamp, 1967.

. Selbstverhältnisse. Stuttgart: Reclam, 1982.

HOULGATE, Stephen. Hegel, Nietzsche and the Criticism of Metaphysics. Cambridge: Cambridge University Press, 1986.

METTENHEIM, Kurt von. Conjunções Críticas da Democratização: as Implicações da Filosofia na História de Hegel para uma Análise Histórica. Instituto de Estudos Avançados da Universidade de São Paulo, USP. Disponível em: www.iea.usp.br/artigos. Última visita em 25/07/2013.

REALE, Miguel. Lições preliminares de Direito. São Paulo: Saraiva, 2010.

RICOEUR, Paul. História e Verdade. Rio de Janeiro: Forense, 1968.

STAËL, Madame de. De l'Allemagne. 2 Volumes. Paris: Garnier-Flammarion, 1968.

Endereço do Autor:

Paço del Rey

36039420 Juiz de Fora - MG.

humbertoschubert@yahoo.com.br 